\title{
A Comparison of Three Dry Matter Forage Production Methods Used in South Africa
}

\author{
A. J. Joubert and W. J. Myburgh \\ Department of Nature Conservation, Tshwane University of Technology, Private Bag X680, Pretoria 0001, South Africa
}

Correspondence should be addressed to W. J. Myburgh; myburghwj@tut.ac.za

Received 22 November 2013; Accepted 11 April 2014; Published 27 April 2014

Academic Editor: Daniel I. Rubenstein

Copyright (C) 2014 A. J. Joubert and W. J. Myburgh. This is an open access article distributed under the Creative Commons Attribution License, which permits unrestricted use, distribution, and reproduction in any medium, provided the original work is properly cited.

\begin{abstract}
A common method for determining forage production of rangelands is by clipping and weighing forage from quadrats with predetermined areas. This technique is however time consuming. Other techniques which require less time and labour include amongst others using the disk pasture meter or phytomass derived from the vegetation classification program PHYTOTAB, in conjunction with the Plant Number Scale, which is used to determine vegetation canopy cover. The phytomass determined using PHYTOTAB/Plant Number Scale and the disk pasture meter was compared to the phytomass obtained from the actual clipping and weighing of forage. Tests showed that there were indeed statistically significant differences between the mean phytomass values of the three techniques. Considerable variation was shown in the results of the disk pasture meter readings compared to the other two techniques. The phytomass values obtained using the disk pasture meter were significantly higher than the phytomass determined using both the PHYTOTAB/Plant Number Scale and the clipping and weighing techniques. Results further indicated a significant similarity in the phytomass determined using the PHYTOTAB/Plant Number Scale and the clipping and weighing technique. The results of this pilot study need further investigation.
\end{abstract}

\section{Introduction}

The ability to accurately measure aboveground phytomass of the grass layer is important in calculating forage availability for grazing and animal stocking rates and it influences the effectiveness of fire when used as a management tool to remove moribund material. According to Harmoney et al. [1] and Sharrow [2], clipped pasture samples are the most accurate and commonly used method for determining phytomass. Clipping is laborious and destroys a portion of the sward sampled. Much effort has been devoted to the development of rapidly measured, nondestructive parameters from which phytomass may be predicted without the necessity of clipping plots. Both pasture height [3] and forage bulk $[4,5]$ have been employed successfully as predictors of pasture phytomass. Forage bulk refers to the volume of forage compressed beneath a plate of known weight [3]. The relationship between forage bulk and pasture phytomass yield generally has been strong with correlation coefficients greater than 0.90 often being reported [4-9]. Because forage bulk is a measure of "compressed volume" of forage, it integrates both sward height and density into a single, three-dimensional quantity. This is believed to explain its value as a predictor of phytomass yield $[4,6]$.

Less tedious methods that do not require clipping would allow managers to take phytomass readings more frequently. This can be particularly useful when, for example, the objective is to determine the amount of forage consumed by livestock and game species within certain seasons. Accuracy of results can also be increased when more samples are taken. The use of the disc pasture meter (DPM) to determine forage phytomass was developed by Bransby and Tainton [3] and integrates sward height and density into one measure, often called bulk height or bulk density [4]. The most practical and efficient method for estimating grass fuel loads is with the DPM and can be applied and used in numerous vegetation types [10]. The technique involves relating the settling height of an aluminum disc dropped onto the grass sward to the standing crop of grass holding up the disc, expressed in kilograms per hectare. This technique can be problematic as estimations may be affected by rocks, rather than grasses, holding up the base plate [11]. There is a simple 
relationship between the settling height and the standing crop of grass provided that the disc pasture meter has been successfully calibrated. Successful universal calibrations have been achieved for much of the grasslands and savannas in Southern Africa [10]. Research and field experience indicate that the calibration developed in the Kruger National Park [12] can be used as a general calibration for estimating grass fuel loads for management purposes in these regions of Southern Africa [13].

The DPM relies on calibrations performed on pure or evenly distributed plant compositions to determine forage phytomass. Commercially available meters come with factory calibrations; however, the accuracy and precision of these equations have not been evaluated for Southern Africa rangeland conditions. Many studies of double-sampling techniques have shown that these techniques require frequent calibration and that universal equations for estimating pasture mass may be unreliable [14]. Previous studies have indicated that universal prediction equations were not useful because of variations in rangeland, management, and climate [14]. The level of error in measuring forage mass varies widely. E. B. Rayburn and S. B. Rayburn [15] and Unruh and Fick [16], however, working in rangelands of Northeast USA, obtained calibration errors with plate meters of about $10 \%$ of pasture yields. They concluded that this level of error is acceptable for farm use.

The Plant Number Scale (PNS) was developed by Westfall and Panagos [17] as an improved method of cover estimation using variable-sized belt transects. This technique is used to determine the canopy cover of all plant species recorded using a quadrat or area-based survey technique. The quadrat size used in this study was $100 \mathrm{~m}^{2}$. Individuals of each species recorded were counted using variable-sized transects. The variability of the transect size (length and width) was dependent on the average canopy size and average spacing between canopies of the same species. The recorded vegetation data are loaded onto a computer and are classified into plant communities using the PHYTOTAB computer program developed by Westfall [18]. PHYTOTAB, using the canopy cover of each grass species recorded, derives both an estimated phytomass $(\mathrm{kg} / \mathrm{ha})$ for each individual grass species and an estimated grass biomass $(\mathrm{kg} / \mathrm{ha}$ ) for each plant community. This method has proved to provide accurate results for estimations of canopy cover and phytomass if field sampling is accurate and precise [19].

Disadvantages of the PNS include reduced precision because of the classes used for crown diameters as well as sometimes insufficient variation being included within transects, especially short transects [20]. A further disadvantage is the difficulty in determining mean crown to crown gap for plants with varied spacing. Spacing can vary considerably for plants with a given cover and density in terms of individuals per hectare [20]. Advantages of the PNS method include being originally developed in South African savannas with less observer bias than many other vegetation assessment techniques $[21,22]$. The provision of species-specific phytomass, density, spacing, and canopy cover estimates via the use of PHYTOTAB $[23,24]$ is an added advantage.
The main objective of this pilot study was to test and compare the grass phytomass derived using the Plant Number Scale with figures obtained using the disk pasture. The clipped and weighed phytomass served as a benchmark for comparison with the phytomass figures obtained using the other two techniques.

\section{Study Area}

The study area is situated in the Dinokeng Nature Reserve within the boundaries of the Kwalata Game Ranch (KGR), located $20 \mathrm{~km}$ north of Pretoria in the Gauteng Province, South Africa, between the southern latitudes $28^{\circ} 20^{\prime}$ and $28^{\circ} 21^{\prime}$ and the eastern longitudes $25^{\circ} 23^{\prime}$ and $25^{\circ} 24^{\prime}$. The altitude of KGR ranges between 1140 and $1120 \mathrm{~m}$ above sea level. The KGR consists of 2500 ha of natural vegetation in a low undulating landscape dominated by sandy plains with vegetation varying from open savanna, riverine to grassland [25]. The tree canopy cover of the study area ranges from $11 \%$ to $20 \%$ and is dominated by woody species of Combretum, Acacia, Ziziphus, and Euclea found on flats and lower slopes primarily on eutrophic sands. The herbaceous layer is dominated by grasses with relatively low basal cover occurring on sandy soils [26].

The study area is situated in the summer rainfall region with very dry winters. Three seasonal distinctions can be made within the area, namely, a cool dry season from May to mid-August, a hot dry season from mid-August to October, and a hot wet season from November to April [25]. KGR has a mean annual rainfall of $500-700 \mathrm{~mm}$ occurring mainly in summer and mean maximum and minimum temperatures of $35^{\circ} \mathrm{C}$ and $-3.1^{\circ} \mathrm{C}$ for November and June, respectively. The KGR consists of two major veld types [26], namely, Mixed Bushveld (veld type 18) and Sourish Mixed Bushveld (veld type 19). The same vegetation was more recently described by Mucina and Rutherford [25] as Central Sandy Bushveld (SVcb12) and Loskop Mountain Bushveld (SVcb 13). The survey sites of the study were, however, restricted to the Central Sandy Bushveld.

The geology of the KGR consists of the layered Bushveld igneous complex (Lebowa), dominated by mafic and ultramafic rocks intruding into the Transvaal Sequence [25]. The KGR falls within the southern parts of the Mixed Bushveld vegetation unit and has an underlining geology consisting of granite of the Lebowa Granite Suite and some granophyre of the Rashoop Granophyre Suite. The most important sedimentary rocks of the Waterberg Group are sandstone, conglomerate, and siltstone of the Alma Formation and also sandstone, siltstone, and shale of the Vaalwater Formation [25]. The soils of the KGR are from either the Hutton or Clovelly soil forms that are well drained and deep, often with catenary sequence from Hutton at the top to Clovelly on the lower slopes. Soils with minimal development also occur, usually very shallow on hard or weathering rock. Lime is very rare or absent in the landscape [25].

\section{Methods}

Three survey sites of no specific dimensions were subjectively selected within the Central Sandy Bushveld portion of the 


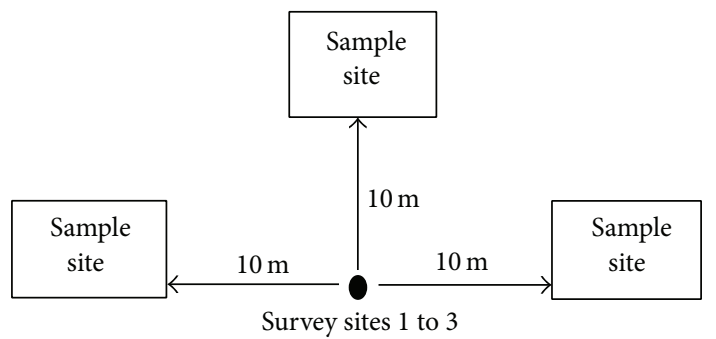

FIgURE 1: Placement of the sample sites at each of the three survey sites located within the Central Sandy Bushveld on Kwalata Game Ranch.

KGR in areas with limited or no woody cover. At each survey site, three sample sites (quadrats) of $100 \mathrm{~m}^{2}$ were placed out ten meters from the survey site center using compass bearings thus providing a total of nine sample sites surveyed (Figure 1). A photographic record was taken at each sample site for reference purposes and the coordinates of all nine sample sites were recorded using a global positioning system (GPS).

All three techniques were used for recording data at the nine sample sites. The DPM was calibrated for each individual survey site before any readings were recorded. The DPM consists of a long central aluminium rod, an aluminium sleeve which slides freely on the central rod, and a disc plate with a diameter of $362 \mathrm{~mm}\left(0.166 \mathrm{~m}^{2}\right)$ attached to it. The central rod is marked at $10 \mathrm{~mm}$ intervals in an upward direction starting at the top end of the sleeve when the under surface of the disc is flush with the lower end of the rod [4]. The combined weight of both the aluminium sleeve and disc plate is $1.5 \mathrm{~kg}$ which is dropped onto the grass underneath the disc to obtain forage bulk readings. The central rod of the DPM is placed perpendicular to the ground surface, while the sleeve with the attached disc is held over the grass sward and dropped from a standard height of $600 \mathrm{~mm}$ above the ground. After the settling height has been recorded, the grass underneath the disc is clipped as close to the ground surface as possible. Each individual clipping was collected and marked. The grass clippings were sundried for a period of three weeks. After the clippings had been dried and weighed, they were used to calibrate the DPM by relating the disc meter settling height $(\mathrm{cm})$ to the grass phytomass $(\mathrm{g})$ of that specific reading [12]. Four DPM readings were recorded within a $5 \mathrm{~m}$ distance from the centre of each survey site. It was purposely decided to record only four DPM readings to determine whether accurate phytomass values can be obtained with limited data. Calibrations for each survey site were calculated, using the mean of the four readings. The calculated value for each survey site was applied to the corresponding sample site at that survey site.

Three sample sites (quadrats) of $100 \mathrm{~m}^{2}(10 \mathrm{~m} \times 10 \mathrm{~m})$ were recorded at each survey site (Figure 1) using the three different techniques. The herbaceous plant species were recorded and canopy cover values determined using the PNS. At the same sample site, a total of four DPM readings were recorded. The mean of these four recordings presented the

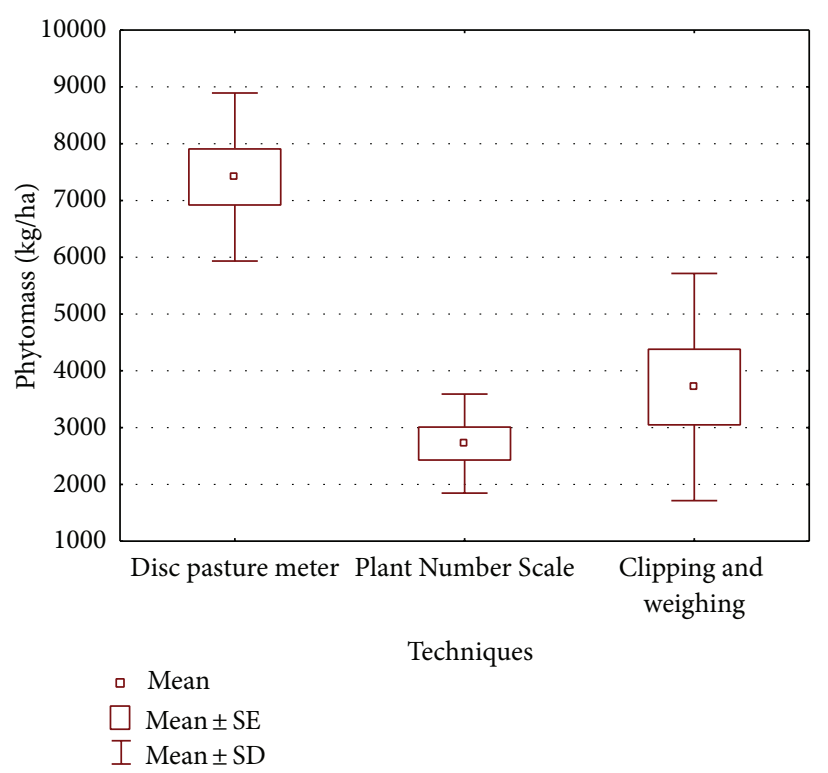

FIgURE 2: Mean, mean \pm SE, and mean \pm SD of phytomass for all three techniques at survey site level.

phytomass $(\mathrm{kg} / \mathrm{ha})$ of the sample site. Lastly, a one-squaremeter frame was subjectively laid out within these quadrats and clipped. One benchmark clipping was done in every quadrat. These clippings were also sundried for three weeks and weighed afterwards.

The one-way analysis of variance (ANOVA) test, which is a statistical technique used to compare the means of two or more samples [27], was used in conjunction with the Tukey test [28]. The Tukey test, also referred to as the Tukey-Kramer method, is a single-step multiple comparison procedure and statistical test comparing all possible pairs of means, based on a studentized range distribution [28].

\section{Results}

The data of the sample sites were analyzed and a total of nine phytomass values $(\mathrm{kg} / \mathrm{ha})$ were calculated for each technique at the three survey sites (Table 1).

The one-way ANOVA analysis of variance statistical test was used to investigate possible differences in results obtained using the different techniques. The analysis indicated statistically significant differences between the mean phytomass values of the three samples, where $n=9$ in each case, at 2 and $24 \mathrm{df}(F=23.767, P<0.05)$ (Table 2$)$.

Once a significant difference was established $(P=$ 0.000002 ), the Tukey test was used to determine which values differed significantly from one another. The results indicated a significant difference in mean phytomass of the clipping and weighing and DPM techniques $(P=0.000203)$. There was not, however, a significant difference between the mean phytomass of the clipping and weighing and PNS techniques $(P=0.363271)$ (Table 3 and Figure 2). 
TABLE 1: Mean phytomass values $(\mathrm{kg} / \mathrm{ha})$ calculated for each sample site at three survey sites using the different techniques.

\begin{tabular}{|c|c|c|c|c|c|c|c|c|c|}
\hline \multirow{3}{*}{ Sample site } & \multicolumn{3}{|c|}{ Disc pasture meter (DPM) } & \multirow{2}{*}{\multicolumn{3}{|c|}{$\begin{array}{l}\text { Clipping and weighing } \\
\text { Survey site }\end{array}$}} & \multirow{2}{*}{\multicolumn{3}{|c|}{ Plant Number Scale (PNS) }} \\
\hline & & & & & & & & & \\
\hline & 1 & 2 & 3 & 1 & 2 & 3 & 1 & 2 & 3 \\
\hline 1 & 9845 & & & 3500 & & & 1852 & & \\
\hline 2 & 7324 & & & 3250 & & & 2101 & & \\
\hline 3 & 8677 & & & 2980 & & & 1258 & & \\
\hline 4 & & 7774 & & & 2060 & & & 3972 & \\
\hline 5 & & 8511 & & & 2560 & & & 2627 & \\
\hline 6 & & 5361 & & & 1600 & & & 3480 & \\
\hline 7 & & & 5478 & & & 3340 & & & 2605 \\
\hline 8 & & & 6621 & & & 6980 & & & 3295 \\
\hline 9 & & & 7134 & & & 7160 & & & 3280 \\
\hline Mean phytomass (kg/ha) & 8615 & 7215 & 6411 & 3243 & 2073 & 5827 & 1737 & 3360 & 3060 \\
\hline
\end{tabular}

TABLE 2: Results of the one-way ANOVA statistical test indicating significant differences between the mean phytomass values of the three techniques.

\begin{tabular}{|c|c|c|c|c|c|c|c|c|}
\hline \multirow{2}{*}{ Variable } & \multicolumn{8}{|c|}{ Marked effects are significant at $P<0.05000$} \\
\hline & SS effect & df effect & MS effect & SS error & df error & MS error & $F$ & $P$ \\
\hline Phytomass (kg/ha) & 110160135 & 2 & 55080068 & 55619236 & 24 & 2317468 & 23.76735 & 0.000002 \\
\hline
\end{tabular}

TABLE 3: Statistical analysis of the differences in phytomass $(M=$ mean phytomass) between the three techniques using the Tukey test.

\begin{tabular}{lccc}
\hline & Marked differences are significant at \\
Techniques & \multicolumn{3}{c}{$P<0.05000$} \\
& $\mathrm{M}=7413.9$ & $\mathrm{M}=2718.9$ & $\mathrm{M}=3714.4$ \\
\hline Disc pasture meter $\{1\}$ & & 0.000130 & 0.000203 \\
Plant Number Scale $\{2\}$ & 0.000130 & & 0.363271 \\
Clipping and weighing $\{3\}$ & 0.000203 & 0.363271 & \\
\hline
\end{tabular}

\section{Discussion}

The survey sites were subjectively chosen to ensure sampling on evenly distributed plant compositions within the Central Sandy Bushveld [25]. Vegetation data obtained using the Plant Number Scale [17] and analyzed using the PHYTOTAB computer package $[18,23]$ confirmed three distinct plant communities within this vegetation type. The three survey sites sampled correlated with the three plant communities identified. Considerable variation was shown in the results of the DPM readings compared to the results of the other two techniques used. The phytomass values for all sample sites, using the DPM, were considerably higher than the values calculated using both the PNS and the clipped and weighing techniques.

Although the phytomass obtained using the DPM greatly exceeded those of the other two techniques, further investigation is needed before distinctive judgments can be made regarding the accuracy of the method. A study done by Bransby and Tainton [3] on the application of the DPM in grazing management clearly indicates that a specific calibration process must be followed to obtain accurate results. The calibration process explained involves the sampling of \pm 14 individual readings opposed to the four readings done in this study. Bransby and Tainton [3] indicated that regression relationships can vary considerably between calibrations and that these relationships may be influenced by rangeland type and conditions (time in the season, disc mass, disc size, etc.). Grass structure and forage type are factors that should be considered when using the DPM. Results from this study showed that the DPM provided the highest phytomass in survey site 1 , which is dominated by the highly fibrous grasses Loudetia simplex and Diheteropogon amplectens. Compared to the results of the other two techniques, it is believed that the DPM tends to overestimate phytomass due to varying settling heights. In the Kruger National Park, Zambatis et al. [11] noticed that the instrument frequently settles above the bulk of the grass leaf mass, leading to the suspicion that the settling height is inflated and nonrepresentative. During the application of the DPM, the operator needs to carefully consider the presence of rocks and even the stems of herbaceous plants other than grasses, since this will definitely influence the settling height of the disc.

The results of this study showed a significant similarity in the PNS's projected phytomass and the actual clipped phytomass for all three survey sites. Although the PNS technique is somewhat labour intensive, the results obtained do provide more accurate estimations of pasture phytomass than the results of the DPM in relation to the benchmark (clipping and weighing). As the study progressed, less time was spent using the PNS technique, suggesting that field worker experience plays a major role in the labour intensity of the method. 


\section{Conclusion}

The results obtained from this pilot study, which was conducted in natural grassland, indicated the importance of grass structure/growth form on disc settling height of the DPM. The phytomass figures generated in grasslands, other than planted pastures, should be used with caution due to the potentially inflated readings. Another area of concern needing more study is that of the universal calibration models/equations used for Southern African grassland and savanna systems. As mentioned, calibration models are influenced by a number of factors such as variations in rangelands, management, and climate of an area $[3,14]$, thus making calibrations area and vegetation specific. Phytomass estimations obtained using the PNS and the PHYTOTAB computer program package compared favourably with the figures of the actual clipping and weighing of grass. This could be a valuable spin-off from techniques that were primarily developed for phytosociological studies. The conclusions are however drawn from data recorded at a limited number of sample sites and it is suggested that the number of sample sites be increased in further studies. The number of calibrations for the DPM and the total number of clippings also need to be increased at each sample site within the Central Sandy Bushveld. The accuracy of the DPM results depends largely on the structure of the dominant grass species at a sample site within a specific vegetation type and it is suggested that the study be extended to other vegetation types.

\section{Conflict of Interests}

The authors declare that there is no conflict of interests regarding the publication of this paper.

\section{References}

[1] K. R. Harmoney, K. J. Moore, J. R. George, E. C. Brummer, and J. R. Russell, "Determination of pasture biomass using four indirect methods," Agronomy Journal, vol. 89, no. 4, pp. 665672, 1997.

[2] S. H. Sharrow, "A simple disc meter for measurement of pasture height and forage bulk," Journal of Range Management, vol. 37, pp. 94-95, 1984.

[3] D. I. Bransby and N. M. Tainton, "The disc pasture meter: possible applications in grazing management," Proceedings of the Grassland Society of Southern Africa, vol. 12, pp. 115-118, 1977.

[4] D. L. Michalk and P. K. Herbert, "Assessment of four techniques for estimating yield on dryland pastures," Agronomy Journal, vol. 69 , pp. 864-868, 1977.

[5] T. L. Powell, "Evaluation of weighted disc meter for pasture yield estimation in intensively stocked dairy pasture," New Zealand Journal of Experiential Agriculture, vol. 2, pp. 237-241, 1974.

[6] C. W. Alexander, J. T. Sullfvan, and D. E. McCloud, "A method for estimating forage yields," Agronomy Journal, vol. 54, pp. 468-469, 1962.

[7] M. E. Castle, "A simple disc instrument for estimating herbage yield," Journal of the British Grassland Society, vol. 31, pp. 37-40, 1976.
[8] R. A. Santillan, W. R. Ocumpaugh, and G. O. Mott, "Estimating forage yield with a disc meter," Agronomy Journal, vol. 71, pp. 71-74, 1979.

[9] J. P. Shrivastava, D. A. Miller, and J. A. Jackobs, "Estimating alfalfa yields," Agronomy Journal, vol. 61, pp. 649-651, 1969.

[10] W. S. W. Trollope and L. A. Trollope, "Fire behavior a key factor in the fire ecology of African grasslands and savannas, in Forest Fire Research and Wild Land Fire Safety," in Proceedings of IV International Congress on Forest Research, Rotterdam, Millpress, D. X. Viegas, Ed., pp. 1-6, 2002.

[11] N. Zambatis, P. J. K. Zacharias, C. D. Morris, and J. F. Derry, "Re-evaluation of the disc pasture meter calibration for the Kruger National Park, South Africa," African Journal of Range and Forage Science, vol. 23, no. 2, pp. 85-97, 2006.

[12] W. S. W. Trollope and A. L. F. Potgieter, "Estimating grass fuel loads with a disc pasture meter in the Kruger National Park," Journal of the Grassland Society of Southern Africa, vol. 3, pp. 148-152, 1986.

[13] S. I. Higgins, W. J. Bond, and W. S. W. Trollope, "Fire, resprouting and variability: a recipe for grass-tree coexistence in savanna," Journal of Ecology, vol. 88, no. 2, pp. 213-229, 2000.

[14] J. Frame, "Herbage mass," in Sward Measurement Handbook, A. Davies et al., Ed., pp. 59-63, The British Grassland Society, Okehampton, UK, 1993.

[15] E. B. Rayburn and S. B. Rayburn, "A standardized plate meter for estimating pasture mass in on-farm research trials," Agronomy Journal, vol. 90, no. 2, pp. 238-241, 1998.

[16] L. J. Unruh and G. W. Fick, "Equations for a commercial rising plate meter to predict yields of orchard grass and white clover pastures," in Agronomy Abstracts, p. 149, ASA, Madison, Wis, USA, 1998.

[17] R. H. Westfall and M. D. Panagos, "The plant number scale- an improved method of cover estimation using variable-sized belt transects," Bothalia, vol. 18, no. 2, pp. 289-291, 1988.

[18] R. H. Westfall, Objectivity in stratification, sampling and classification of vegetation [Ph.D. thesis], Department of Botany, University of Pretoria, Pretoria, South Africa, 1992.

[19] J. M. Van Staden, Die fitososiologie van die Steenbokpan omgewing in die noordwes-Transvaal [M.S. thesis], Department of Botany, University of Pretoria, Pretoria, South Africa, 1992.

[20] S. M. Abeare, Dry season habitat and patch selection by African buffalo herds: test of a new home range estimator [M.S. thesis], Faculty of Natural and Agricultural Sciences, University of Pretoria, Pretoria, South Africa, 2004.

[21] J. Braun-Blanquet, Pflanzensoziologie, 1 Aufl., Springer, Wien, Austria, 1928.

[22] J. Braun-Blanquet, Pflanzensoziologie-Grundzüge der Vegetationskunde, 2. Aufl., Springer, Wien, Austria, 1951.

[23] R. H. Westfall, G. K. Theron, and N. Rooyen, "Objective classification and analysis of vegetation data," Plant Ecology, vol. 132, no. 2, pp. 137-154, 1997.

[24] R. H. Westfall and A. Greeff, "A national grid of vegetation monitoring sites," South African Journal of Science, vol. 94, no. 4, pp. 150-151, 1998.

[25] L. Mucina and M. C. Rutherford, The vegetation of South Africa, Lesotho and Swaziland, vol. 19 of Strelitzia, South African National Biodiversity Institute, 2006.

[26] J. P. H. Acocks, "Veld types of South Africa," Memoirs of the Botanical Survey of South Africa, vol. 57, pp. 1-146, 1998. 
[27] D. S. Moore, G. P. McCabe, and B. Craig, Introduction to the Practice of Statistics, W H Freeman \& Co, 4th edition, 2003.

[28] R. Lowry, One Way ANOVA-Independent Samples, Vassar Education, 2008. 

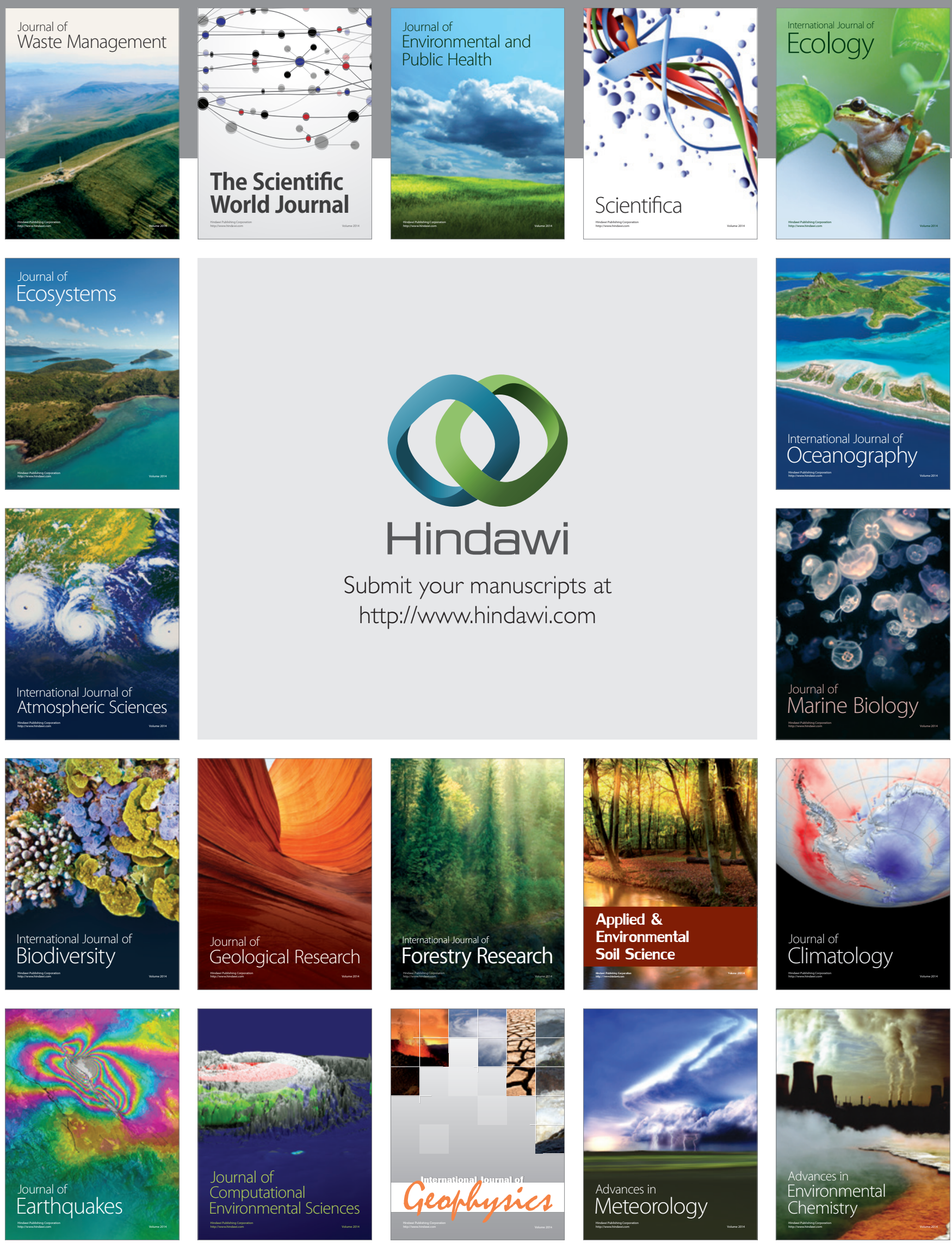